\title{
Interactions among Land, Water, and Vegetation in Shoreline Arthropod Communities
}

\author{
Randall D. Willoughby and Wendy B. Anderson \\ Department of Biology \\ Drury University \\ 900 N. Benton Avenue \\ Springfield, Missouri 65802 USA
}

Received: November 12, 2003

Accepted: May 4, 2004

\begin{abstract}
We investigated the distribution and abundance of terrestrial spiders as a function of their distance from a body of water and the structure of vegetation that would provide suitable habitat. We hypothesized that spiders would prefer to be located near the water to catch abundant aquatic emergent insects. In Montana along the Upper Missouri River, and in Missouri at various locations around Table Rock Lake, transect lines were run from the water's edge to 25 meters inland. At five-meter intervals, in one square meter plots, the number of spiders, number of prey and type, and vegetation type and structure were recorded. In both Montana and Missouri, spider distribution was more strongly associated with available vegetation structure than with distance from shore. This suggests that, although prey availability may be important for predator distribution, suitable habitat is as strong or stronger a determinant for web building spiders.
\end{abstract}

\section{INTRODUCTION}

Ecosystems are almost always connected to other ecosystems. A greater number of mobile entities such as animals and detritus can move from one ecosystem into a nearby ecosystem [1-3]. Whether it is from water to land or from land to water, the movement of those entities can influence the functioning of the recipient communities [4]. According to Polis et al. [2]. "Movements of nutrients, detritus, prey, and consumers among habitats are ubiquitous in diverse biomes and can strongly influence population, consumer-resource, food web, and community dynamics." A few studies have shown that terrestrial consumers such as spiders, other arthropods, and some vertebrates living in riparian zones or coastal zones have diets that consist of a large proportion of aquatic prey $[2-4,6,7]$. Thus, these consumer species are often distributed in high abundances near bodies of water.
Although the distribution and abundance of organisms is often determined by both availability of resources and biotic interactions such as competition, predation, or mutualism, these may not be the only interactions between species. Some species provide habitat for other species and hence determine the distribution of those species [5]. This may include species that engineer habitats that other species use (e.g., caterpillars tying leaves, [5]) or species that are habitat for other species (e.g., plants for animals).

Although few scientists have studied the distribution of terrestrial consumers (e.g., spiders) in communities adjacent to a body of water [1, 3, 4], aquatic prey may be important resources for these terrestrial predators. Therefore, we will test the following two hypotheses.

First, spiders locate their webs closer to a body of water because it is a source of emergent aquatic insect prey such as mosquitoes, may flies, gnats, and other 
flies. Therefore, orb webs will be more abundant closer to the water and those webs will have higher abundances of captured prey of aquatic origin than webs located further from the water. Alternatively, regardless of distance to the water, spiders build their webs in suitable, "architecturally sound" vegetation within the river or lakeshore zone.

To test these hypotheses, we sampled spider communities along the edge of the Upper Missouri River in Montana and along the lake shore of Table Rock Lake in Taney County, Missouri, USA.

\section{METHODS}

We collected data from a 150-mile length of the Upper Missouri River from Fort Benton, Montana to Kipp State Park, Montana, USA. Data was collected during a ten-day float trip that took place June 2-12, 2003. We also completed an equivalent sampling at Table Rock Lake in Taney County in southern Missouri from July 1112, 2003.

Sampling occurred at ten sites in Montana where our canoe group stopped for lunch or to camp. These sites were usually low-sloped sandy or gravel bars on the inside curve of the river. At each site, we haphazardly established three transect lines that were approximately 25 meters apart, and placed the zero meter mark at the water's edge. Each transect continued inland for 25 meters if unobstructed. We made observations within one square meter quadrants along each transect at the 0,5 , $10,15,20$, and 25 meter marks for a total of six data points for each transect. At each point we counted the number of orb webs and web building spiders located between the ground and the top of the vegetation, the number and type of prey in the web, and the number of ground spiders. If spiders were visible, we also recorded a brief description of the spiders for identification purposes. Insect prey in webs were identified as taxa known to emerge from aquatic habitats or from terrestrial habitats. Nearly all prey found in webs were of aquatic origin. Although our hypothesis did not initially consider ground spider abundance and distribution, ground spiders were more common and evident than web building spiders and thus easy to spot and count.
At each sampling point, we also recorded the architecture of the vegetation, vegetation type, and landscape structure. We created an index for the vegetation type to simplify data analysis. The index ranges from 0 for no structural complexity to 10 for high structural complexity.

$$
\begin{aligned}
& 0=\text { Bare Ground } \\
& 1=\text { Short Grass }<5 \text { inches }(13 \mathrm{~cm}) \\
& 2=\text { Tall Grass }>6 \text { inches }(15 \mathrm{~cm}) \\
& 3=\text { Short Herbaceous Plants } \\
& 4=\text { Tall Herbaceous Plants } \\
& 5=\text { Rosaceous Plants } \\
& 6=\text { Thick Rosaceous Plants } \\
& 7=\text { Dead Brush } \\
& 8=\text { Tree Saplings } \\
& 9=\text { Shrubs } \\
& 10=\text { Impassable Shrubs }
\end{aligned}
$$

We performed one way analyses of variance on total spider density, web spider density, ground spider density, and prey density as a function of distance from shore and land form for both Montana and Missouri data. Differences among means were considered statistically significant at the 0.05 probability. We also investigated the relationships between vegetation index and total spider density, ground spider density, web spider density, and prey density with a linear regression. We also plotted regression lines for relationships of these dependent variables to distance from the shore.

\section{RESULTS}

The relationships between spiders and distance from shore differed for Montana and Missouri. At the water's edge $(0-1 \mathrm{~m})$ in Missouri, both web building and ground spiders were denser than they were further inland (Figure 1a). In contrast, most of Montana's spiders were found at greater distances from the river shoreline $(25 \mathrm{~m}$; Figure 1b). The relationship between distance and vegetation index in Montana indicated that vegetation at the water's edge was relatively short and structurally simple, but increased in height and complexity as the transect ran inland (Figure 1d). In Missouri, though, the relationship between distance and vegetation index indicated that the vegetation was most structurally complex at the water's edge (Figure 1c). As 


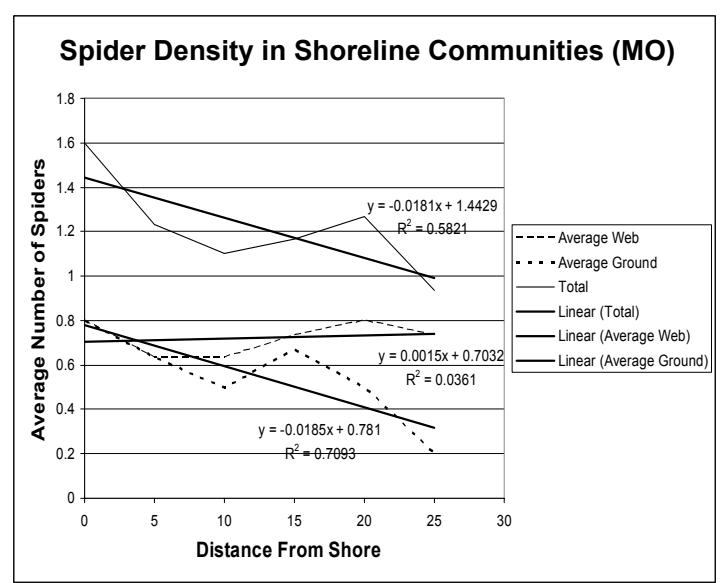

(a)

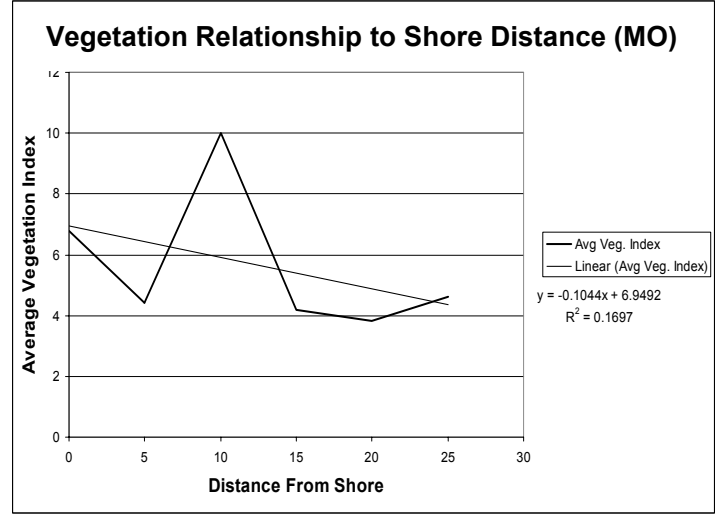

(b)

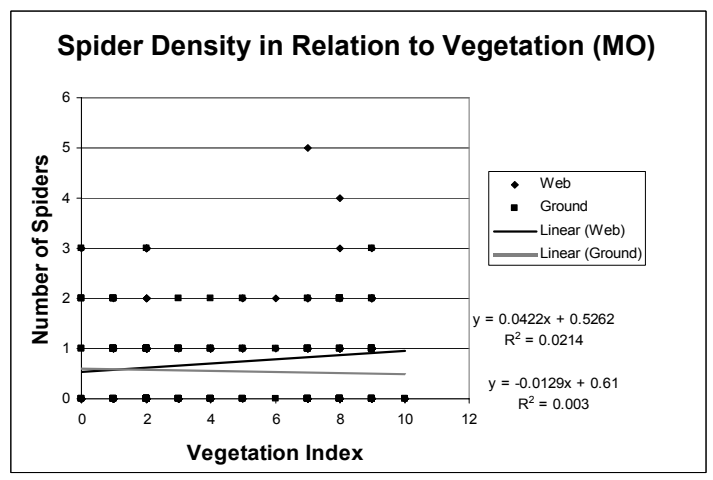

(e)

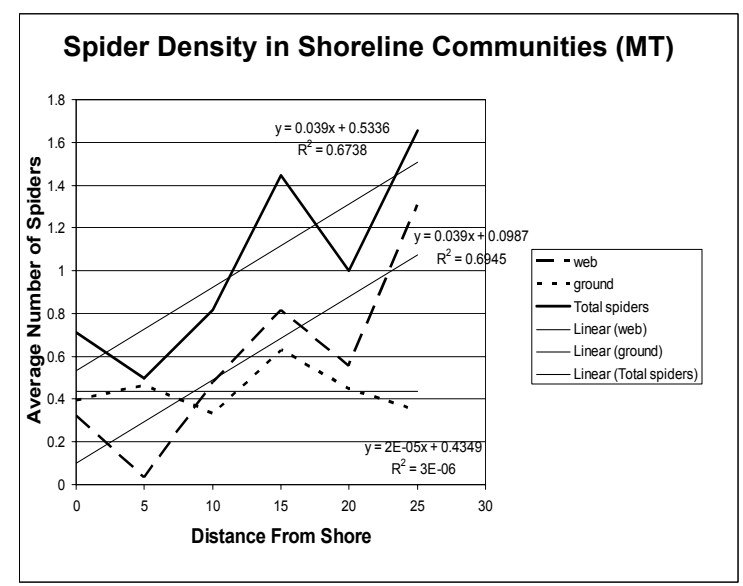

(b)

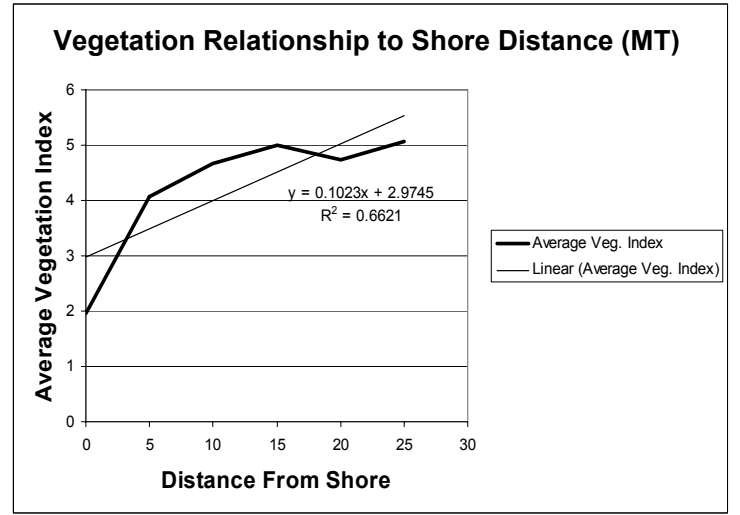

(d)

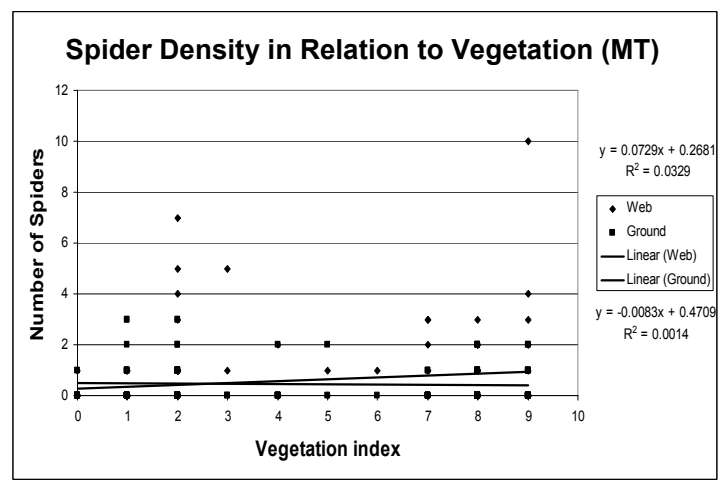

(f)

Figure 1. Graphs (a), (c), and (e) show relationships from Table Rock Lake, Missouri, and graphs (b), (d), and (f) show the same relationships on the Upper Missouri River in Montana. Graphs (a) and (b) show the relationship between distance from the shore and average number of spiders. Graphs (c) and (d) show the relationship between distance from shore and average vegetation index. Graphs (e) and (f) show the relationship between vegetation index and number of spiders. 


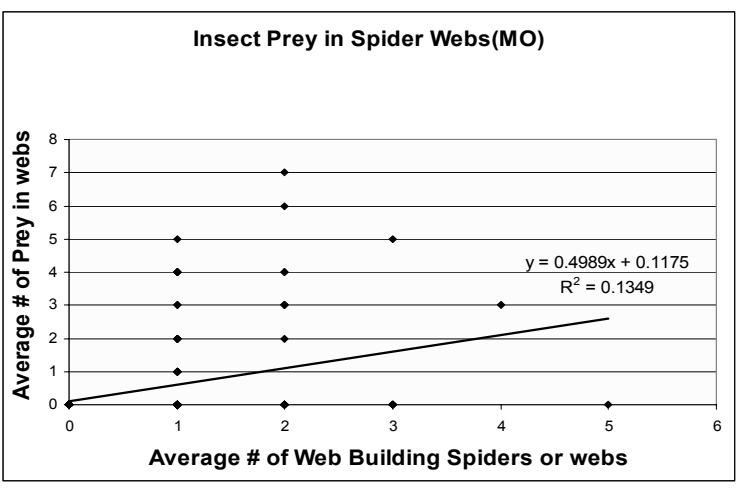

(a)

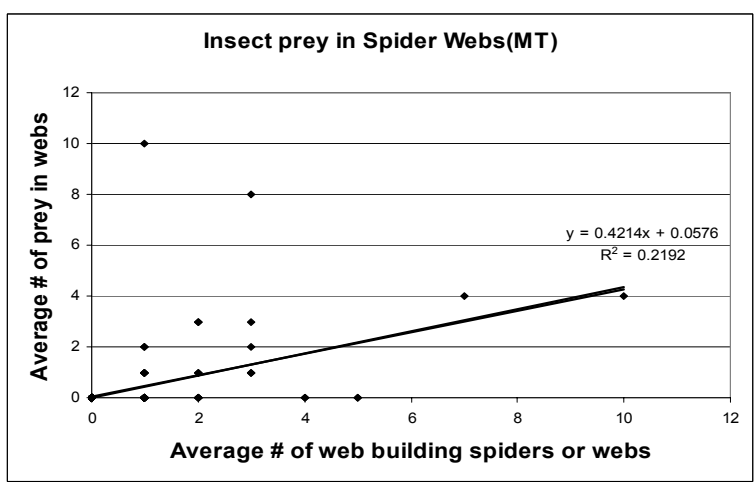

(b)

Figure 2. These graphs show the relationship between average number of web building spiders and average number of prey found in the webs in Missouri (a) and Montana (b).

the Missouri Spider Density in shoreline communities in Missouri transects ran inland, the vegetation index decreased then gradually increased again by $25 \mathrm{~m}$ from shore.

In both Missouri and Montana, web building spiders were found in greater numbers in areas that have a higher vegetation index, with a weak or nonexistent relationship to the distance from water. Ground spiders exhibited no relationship to the vegetation index (Figures. 1e and 1f). In Montana, the web building spider density increased further inland because vegetation index increased, and vegetation index increased as the distance from shore. The opposite was found in Missouri. As the distance from shore increased, the vegetation structure decreased, as did the spider density.

More aquatic emergent insects were observed in spider webs in Missouri (Figure 2a) than in Montana (Figure 2b). As the average number of prey increased in both Missouri and Montana, the average number of web building spiders increased. Prey were overall more abundant in Missouri (0.47 prey per sampling point) than they were in Montana ( 0.30 prey per sampling point).

Assessing the variation in vegetation structure as a function of landform, there was one profound difference between Missouri (Figure 3a) and Montana (Figure 3b). Missouri's water level vegetation was much more complex than vegetation at the water's edge in Montana. With sampling sites being restricted in
Missouri by boat access (much larger than a canoe) there were very few drop offs that we were able to locate. However there is one landform that was very similar: the slopes of both Montana and Missouri were similar in vegetation. They both were a combination of tall herbaceous plants and rosaceous plants.

\section{DISCUSSION}

The object of this study was to determine whether or not spiders are distributed along a shoreline in relation to distance from the shore, which would determine prey availability. Due to cool air and water temperatures in Montana, aquatic emergent insects were not as abundant as we had expected, and patterns of spider distribution were not directly associated with prey availability. Therefore, we also investigated how spiders were distributed in relation to available vegetation. In the comparative study in Missouri, vegetation structure and prey availability were potentially both important.

In Montana a trend in spider location and density was apparent. Farther inland, the vegetation generally increased in size and structure, and spider counts increased with vegetation size and structure as well. The spiders in Montana apparently were not distributed in relation to aquatic prey availability directly, but were located in vegetation that was structurally complex enough to support webs. Stronger and larger plants provide a better structure for web building. Thus any relationship 


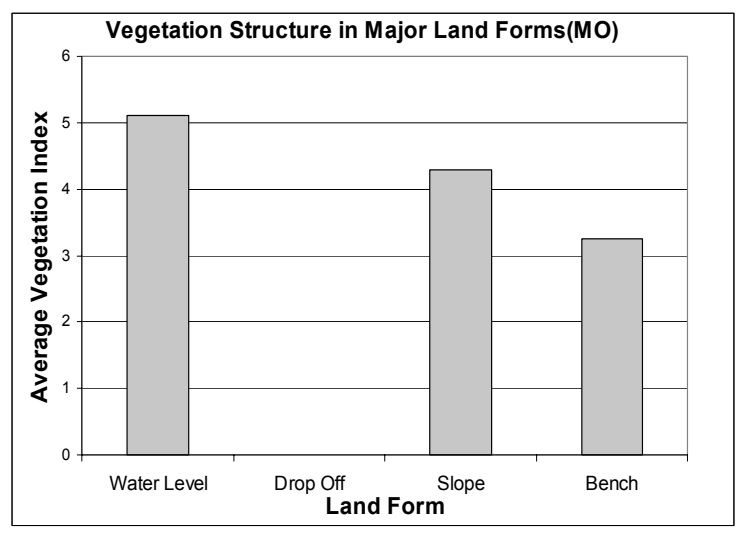

(a)

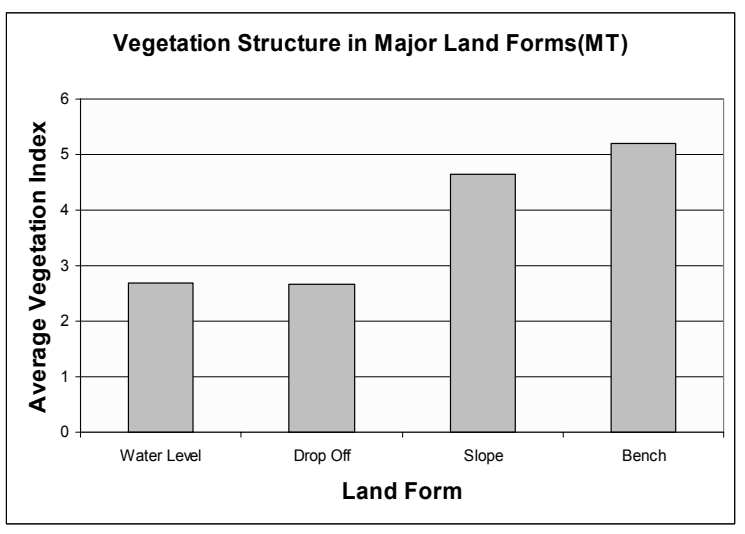

(b)

Figure 3. These graphs show the relationship between land form and average vegetation indexes in Missouri (a) and Montana (b).

between spider density and distance from the shore was a function of vegetation structure (habitat availability), while a relationship to aquatic prey availability was not evident. However, it is important to note that vegetation structure itself is influenced by distance from the water and landform.

In Missouri, the spiders also were not distributed in direct relation with aquatic prey availability, but rather with vegetation availability. Insect prey were not more abundant at the shoreline but were evenly distributed along the length of the transect, whereas spiders were more abundant at the shore. In contrast with Montana shorelines, the shoreline in Missouri had much denser vegetation at the water's edge but vegetation became less dense farther inland. The spider density apparently decreased as the distance increased but this was primarily due to decreases in vegetation structure with increased distance.

Although we hypothesized that spiders would prefer to build webs or be located near a body of water because of the potential prey that may emerge from the water, spiders were not associated with distance from shore, but rather were more associated with the vegetation structure. The patterns in spider location were much stronger in Missouri than in Montana. The reason for this pattern is likely that the vegetation at the water's edge is more structurally complex in Missouri. Table Rock Lake, a dammed reservoir, has minimal fluctuation of the water level, while the Upper Missouri River in Montana fluctuates greatly on a seasonal basis. The shoreline in Montana is often flooded by high water, which scours out most of the low stature vegetation.

This study does not provide evidence that terrestrial spider communities are dependent on resources originating in water. Although other studies have shown that terrestrial consumers prey upon insects emerging from aquatic habitats or resources $[2-4,6,7]$, our study does not directly show that. Instead, spider communities are more dependent on structure of vegetation rather than distance from shore. However, if we sampled each site over a longer period of time that might encompass emergence events of aquatic prey, we would be able to examine the combined effects of or interactions between prey availability and habitat availability.

\section{ACKNOWLEDGEMENTS}

The authors would like to acknowledge the funding from the Heuer Foundation and Drury University. We also would like to thank the Wild Rockies Tour guides Dan Ward and John Willard for their help in the field.

\section{REFERENCES}

1. S. Nakano, H. Miyasaka, and N. Kuhara, Ecology 80, p. 2435( 1999).

2. G.A. Polis, W.B. Anderson, and R.D. Holt, Annu. Rev. Ecol. Syst. 28, p. 289 (1997). 
3. G.A. Polis and S.D. Hurd, American Naturalist 147, p. 396 (1996).

4. J.L. Sabo and M.E. Power. Ecology 83, p. 3023 (2002).

5. J.T. Lill and R.J. Marquis, Ecology 84, p. $682(2003)$.
6. L.J. Gray. American Midland Naturalist 129, p. 288 (1993)

7. G.A. Polis and S.D. Hurd. Proceedings of the National Academy of Science (USA) 92, p. 4382 (1995).

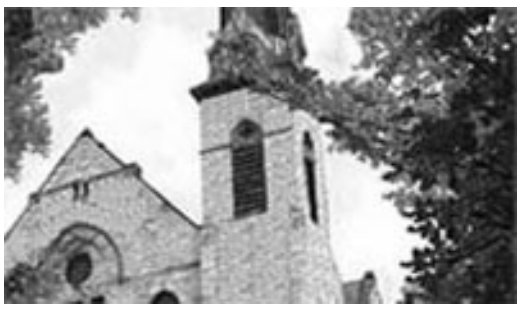

Drury University offers bright, achieving students a commitment to personalized education and diversity. Students expect-and are expected-to explore great ideas and confront questions that will successfully prepare them for dynamic careers and enhanced lives as active global participants. A Drury education combines professional training with the liberal arts. http://www.drury.edu

\section{University of Northern lowa}

\section{Center for Energy and}

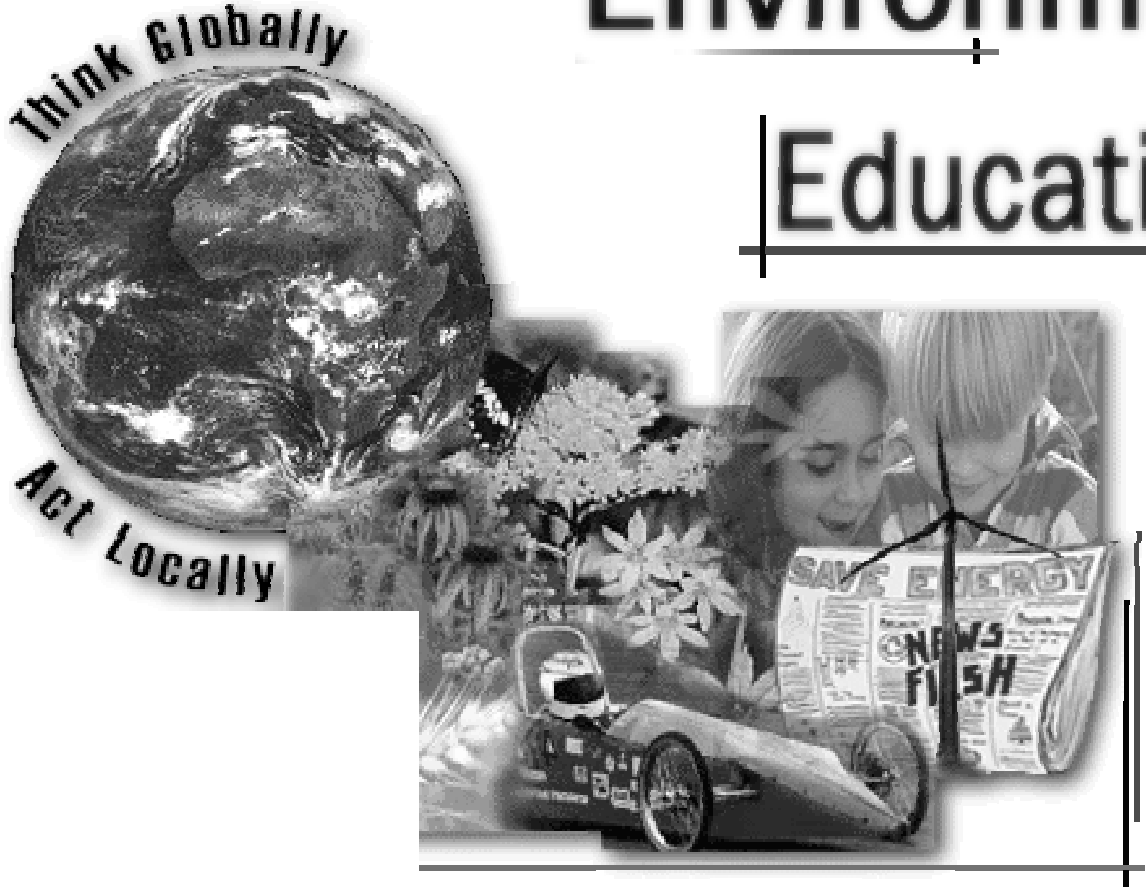

http://www.uni.edu/ceee/ 